\title{
Exploration of Optimal Allocation of Public Sports Resource in China
}

\author{
Guangyao Qi, Changjiang Yi \\ Physical Education College, Baoshan University, Baoshan Yunnan , 678000, China
}

Keywords: Public sports resource in China, Allocation, Optimization

\begin{abstract}
Public sports resource is the foundation of improving people's physical quality and cultivating lifelong sports awareness. But at present, a large contradiction exists between public sports resource allocation in China and people's sports demand. How to optimize public sports resource allocation becomes a problem that relevant departments urgently need to solve. Next, this paper will analyze sports resource allocation and optimization standards from the theory of optimal allocation of sports resource, then investigates the barriers in optimal allocation of public sports resource in China and proposes the specific measures and suggestions about optimal allocation of sports resource. Optimization of public sports resource can promote transformation of public sports service and improve people's life. With the improvement of living standards, people pay more attention to fitness, so their demand for public sports resource is on the rise. Influenced by space, economy and other factors, public sports service is not perfect enough and cannot meet people's physical exercise demand. Thus, relevant departments must transform the idea of sport resource optimization, explore the new optimization way again and provide more adequate conditions for people's physical exercise.
\end{abstract}

\section{Introduction}

Public sports resource is the generic term of conditions and elements which are required by public sports products and services and provided by the society. Public sports resource include people, material and other tangible resources as well as intangible resources such as information, management and policy.

\section{Theoretical analysis of optimal allocation of sport resource}

\section{Description of sport resource allocation}

Sports resource refers to all sports-related resources for sports activities, production and service etc., including tangible and intangible resources. Resource allocation refers to selection of scarce resources through comprehensive analysis of the purpose and significance[1]. Effective resource allocation is first proposed in microeconomics. Effective resource allocation means to reach the largest economic benefit with the fewest resources through rational allocation and utilization. The introduction of effective resource allocation in sports resource can be understood as the most scientific and rational allocation of scarce sports resource through reasonable distribution, utilization and comparison of different purposes so as to meet social demand for physical exercise to the largest extent.

\section{Requirements of optimal allocation of sports resource}

Sport resource optimization should have certain requirements and standards in order to judge whether sport resource is optimized and judge the optimization effect. In sport resource optimization, Pareto criterion is generally adopted. Pareto criterion includes Pareto optimality and Pareto improvement. The main function of Pareto criterion is to measure rationality of social resource allocation. The research and use of Pareto criterion are based on a hypothesis. If no Pareto improvement exists under an established resource allocation state. In other words, in such state, any change can neither make one improve nor make one's situation deteriorate. Such resource allocation 
belongs to the optimal resource allocation. On the contrary, under an established resource allocation state, Pareto improvement exists. In other words, a condition under improved state can make at least one improve, but cannot make one deteriorate. Such state is not the optimal state of Pareto, and there is improvement possibility[2]. Hence, Pareto improvement is an effective method and basic standard of reaching Pareto optimality.

\section{Ultimate goal of optimal allocation of sports resource}

The basic goal of China to construct a harmonious society is to construct a harmonious socialist society with Chinese characteristics, transform government functions, enhance government's public service functions, solve the matters closely related to common people and optimize public resource allocation. Relevant documents about sports work improvement also explicitly indicate the optimal allocation direction of sports resource. Public sports cause as a public welfare cause needs the support of government and relevant departments. The government should take active part in public sports service construction, improve public sports service ability and offer equal public sports service resources for the masses. The same viewpoint is also mentioned in the relevant documents issued by the State Council and General Administration of Sport of China.

\section{Barriers in optimal allocation of public sports resource in China}

\section{Government function transformation is not thorough}

The purpose of government function transformation is to become a service-oriented government which offers service for the society and people's development. However, it is seen from resource allocation mode in Chinese sports field that, government function transformation in China is not thorough. Firstly, sports resource allocation mode in China still adopts the allocation mode in the period of planned economy. The government allocates sports resource as planned. Meanwhile, the common administrative means is still adopted in management process. Besides, sports resource utilization is also supervised through uncompromising government power. Thus, sports resource management and application are monopolized by the government so that certain barriers exist in sports resource procurement, utilization and allocation. Thus, sports resource allocation effect is poor, and the allocation efficiency is low. Sports resource allocation cannot be optimized through Pareto improvement standard. Pareto optimality state cannot be reached[3]. As the reform of market economy deepens, original sport resource allocation cannot meet the demand of contemporary society, so the reform of sports system becomes inevitable. Government's macro-control plays a great role in sports system construction. It is difficult to integrate the two, and they have certain contradiction. Thus, government function transformation is not thorough enough, and the functional orientation is not clear.

\section{Sports resource allocation structure}

At present, sports resource allocation structure in China has many unreasonable phenomena. The state pays insufficient attention to different sports events, so sports resource allocation inclines. Competitive sports has profound significance for state development and international position improvement. Hence, the state pays excessive attention to social value of competitive sports and has obvious particular emphasis on competitive sports resource allocation, but the state neglects people's daily sports events. Thus, serious unbalance situation exists in sport resource allocation structure in China. In accordance with the funds invested in different sports cause, the fund input in competitive sports is 2.5 times of public sports input. Thus, competitive sports development in China is rapid and even unprecedented. Public sports development in China is slow and even lags behind other countries[4]. In addition, national development strategic objective for Olympic Games has great difference with development goal of National Games of PRC, which also makes national sports resource allocation and subordinate provincial and urban sports resource allocation present unbalanced state. The excessive investment in competitive sports has gained some achievements, but 
it also results in serious resource waste. Public sports resource is still in the scanty state and cannot satisfy the demand of people's physical exercise.

\section{Sports market system}

The development of sports industry in China is in the transitional period. In the reform process, market position of sports industry and resource allocation foundation should improve. Currently, Chinese sport resource is influenced by planned economy and dominated by directive plan and guiding plan. These planning systems lead to low resource allocation efficiency and deviate from contemporary market economy, which causes technological obsolescence and stagnation. Meanwhile, effective development cannot be gained, and economic situation worsens continuously. It is found from Pareto criterion that, it is a typical Pareto low-efficiency state. Besides, sport resource allocation mode in the market also has some defects. Firstly, sports resource management mechanism and management system do not comply with market economy, which makes sports resource market system and market mechanism unsound and makes sports resource allocation not in conformity with market standards. Secondly, competition subjects in the market have not strong independence, or they only have short-term independent behavior, thus leading to the rise in market transaction cost limit. Thirdly, non-competition industry and relevant organization departments seize abundant resources in scarce resources, thus leading to resource waste and low use efficiency. Finally, industry policy and economic accounting system are imperfect, which gives rise to many shortcomings in resource development and utilization. Based on the above analysis, the reasons for low resource allocation efficiency are diversified.

\section{Economic development in different regions is unbalanced}

Sport resource allocation is closely related to economy, culture and other social factors. Unbalanced economic and cultural development in each region results in the gap of sports industry in different provinces and regions. Social development degree and people's living standard play a decisive role for the position of sports in market economy. Only the improvement of economic level, people's living standard, values and spiritual level can facilitate development of sports industry. The development situation of sports industry in China obviously highlights regional difference. There is a huge gap in sports industry development between developed regions and backward areas. Seeing from regional distribution in China, eastern region is obviously superior to western area. At the same time, driven by benefits, sports industry resources are also unbalanced in internal distribution, and polarization phenomenon is serious. For some great competitions or internationally influential sports events and sports events with ornamental value, sports industry resource can create larger value. These sports events can effectively attract all kinds of resources and investments, such as basketball, football and other sports events. Conversely, some small competition events that people are unfamiliar with have weak social financing ability and talent reserve ability, and mainly depend on government funding in project implementation and competition holding. So, resource allocation of these sports events is relatively weak.

\section{Countermeasures on optimization of public sports resource allocation}

Resource allocation optimization can be only based on theatrical research and cannot be reached in practice. Thus, resource allocation rationality has some limits. In practice, we need to rationally allocate sports industry resources, reduce resource transaction cost, improve resource utilization rate and regard pursuit of higher Pareto efficiency as the goal. Based on the above analysis, the author proposes several optimization measures and suggestions on optimal allocation of public sports resource in China.

\section{To specify government orientation and optimize market resource allocation}

Firstly, the government should specify its orientation in sports resource allocation, transform government functions to indirect and macroscopic management mode from direct and microcosmic 
management mode, follow the function of market mechanism in sports resource allocation, establish management and development policy and scheme of sports industry according to actual market demand, rationally adjust the structure of sports industry and make Pareto efficiency become possible. Therefore, optimization of sports resource allocation cannot be separated from sound market mechanism and government's macro-control function. Market development rules should be utilized to adjust the structure of sports industry. Meanwhile, government's policy and legal means can be used to solve the limitation of market mechanism in resource allocation optimization. As early as 5 years ago, the State Council specifically proposed the requirements for sports resource allocation in the guiding opinion on development of sports industry - to transform government functions, eliminate trade monopoly, firmly execute separation of government functions and enterprise management as well as separation of profit and non-profit. In addition, it is required to fully follow market development rules in sports resource allocation and eliminate all monopolistic behaviors for sports market resource. Through interpreting relevant opinions, we can see China has clearly realized the key points restricting China's sports development, which makes transformation of sports management mode become possible.

\section{To improve sports market management mechanism}

Market mechanism is utilized to regulate sports resource allocation. Through the joint function of price level and competitive mechanism, sports resource is allocated where the maximum benefit can be generated. But, this analysis is based on the perspective of economics. Sports cause has the property of public welfare which is not closely related to economy. Thus, certain contradiction will inevitably exist if it is mentioned in the same breath with economics with strong profit pursuing trend. At this time, the government must intervene in the market and perfect sports market management mechanism. Furthermore, market economy is also legal economy. Some activities which break away from legal constraint will easily trigger serious negative effects, so legislation is required in optimal allocation of sports resource[5]. At present, China has issued some laws and regulations on sports resource allocation and guiding opinions on sports resource reform. It can be seen from analysis of these materials that, sports resource allocation in China gradually inclines to group sports from sports resource allocation. Thorough sports mechanism needs effective legal constraints. So, relevant departments must formulate corresponding policies and regulations according to sports resource development demand and create good conditions for sports resource allocation.

\section{To improve social supervision institution setting}

China is short of sports resource, which is an incontestable fact. It is hard to complete resource allocation optimization in a short term. Hence, it is required to not just enhance sports resource supply in sports resource allocation process, but also rationally allocate limited resource. For the above behavior, all sectors of society have supervision right and obligation. Firstly, public sports resource allocation requires democratic supervisory mechanism and should be open and transparent. For significant sports resource allocation, hearing is required to improve the participation degree of social people and boost optimal resource allocation efficiency. Secondly, non-profit supervisory organization should be set up. The organization should not merely implement supervision function, but also objectively publish public sports resource allocation mode and specific use conditions on behalf of the third party. These measures can effectively reduce sports resource waste and optimize sports products and services.

\section{Conclusion}

In conclusion: public sports resource allocation concerns livelihood issues, so Chinese relevant departments must strictly deploy and rationally execute it. However, since China takes no count of public sports resource and the government excessively intervenes, sports resource allocation optimization is difficult to complete. Thus, Chinese sports management departments must see clearly 
the factors limiting sports resource allocation optimization, overcome them one by one and strive for minimization of Pareto efficiency.

\section{Acknowledgement}

This paper belongs to the topic of Baoshan University; topic title: Analysis of Idle State of Sports Venue Resource in Western Yunnan and Market Development; No.: 14BY014; it also belongs to the science and technology project approval topic of Baoshan City; topic title: Study on Community Sport in Community Sport under Nationwide Fitness View.

\section{References}

[1] Tang Wei, Optimal Allocation of Rural Sports Resource under Background of Balancing Urban and Rural Development - Case Study of Rural Sports in Rural Sports Province. Sport Science and Technology, 2015,36(2):18-19.

[2] Bi Hongxing, Research on Urban Public Sports Facilities Planning Layout in China. Journal of Chengdu Sport University, 2012,38(4):34-38.

[3] Xie Qi, Study on Western Rural Sports resource Allocation-Case Study of Shaanxi Province. Fighting, 2012,04(7):6-7.

[4] Wen Jin, Analysis of Current Situation and Countermeasures of Public Sports Service Equalization in China. China Science \& Technology Panorama Magazine, 2014(10):279-279,281.

[5] Chen Yuanyuan, Exploration of Equalization Path of Rural Public Sports Service. Adult Education, 2011,31(11):116-117. 